\title{
Anthraquinonyl glycoside facilitates the standardization of graphene electrodes for the impedance detection of lectins
}

\author{
Bi-Wen Zhu ${ }^{\dagger}$, Liang Cai ${ }^{\dagger}$, Xiao-Peng He* ${ }^{*}$ Guo-Rong Chen and Yi-Tao Long ${ }^{*}$
}

\begin{abstract}
Background: Construction of electrochemical impedance sensors by the self-assembly technique has become a promising strategy for the 'label-free' detection of protein-ligand interactions. However, previous impedance sensors are devoid of an inherent electrochemical signal, which limits the standardization of the sensors for protein recognition in a reproducible manner.

Results: We designed and synthesized an anthraquinonyl glycoside (AG) where the anthraquinone (AQ) moiety can bind to the surface of a graphene-based working electrode while the glycoside serving as a ligand for lectin. By measuring the inherent voltammetric signal of $\mathrm{AQ}$, the glycosides decorated on the working electrode could be simply quantified to obtain electrodes with a unified signal window. Subsequently, impedance analysis showed that the 'standardized' electrodes gave a reproducible electrochemical response to a selective lectin with no signal variation in the presence of unselective proteins.
\end{abstract}

Conclusion: Anthraquinone-modified ligands could be used to facilitate the standardization of electrochemical impedance sensors for the reproducible, selective analysis of ligand-protein interactions.

Keywords: Anthraquinone, Graphene, Glycoside, Lectin, Electrochemistry, EIS, Standardization

\section{Background}

Sugars distributed on the surface of mammalian cells are key informational molecules for cell-cell recognition and adhesion through the interaction with lectins (sugar recognition proteins). Unquestionably the ability to probe sugar-lectin recognitions may boost the advancement of the glycomics. However, conventional approaches for analysis of these interactions mainly rely on immunofluorescence techniques, which are time-consuming and expensive. As a result, a number of 'label-free' methods for the quick and economic detection of lectins have been developed [1-5].

Among the various methods introduced, electrochemistry, because of its ease in manipulation and good sensitivity, has been widely employed for lectin analyses $[3,5,6]$. In addition, electrochemical techniques generally

\footnotetext{
* Correspondence: xphe@ecust.edu.cn; ytlong@ecust.edu.cn

${ }^{\dagger}$ Equal contributors

Key Laboratory for Advanced Materials \& Institute of Fine Chemicals, East China University of Science and Technology, 130 Meilong Rd, Shanghai
} 200237, PR China do not require heavy facilities for signal output. Electrochemical impedance spectroscopy (EIS) can sensitively interpret the resistive ability of an interfacial species, which has been broadly applied in the study of corrosion science as well as development of label-free sensors. EIS sensors for lectins, based on the gold-alkenethiol selfassembly technique, have provided promising means for the concise, label-free detection of lectins and live cells that express a glyco-receptor [7-15].

Nevertheless, while the use of gold as working electrode may increase the detection cost, the standardization of electrodes remains difficult due to the lack of an inherent signal 'reporter'. To address these issues, we report here the design and synthesis of an anthraquinonyl glycoside (AG) in which the anthraquinone moiety can simultaneously serve as a 'binder' for a graphene-based electrode and a reporter that produces an electrochemical signal to standardize the sensor fabrication. By using voltammetry, the AGs decorated on the graphene-based electrodes can be easily quantified, thereby facilitating the standardization of the electrodes to produce a unified signal window for 
lectin detection. Subsequently, EIS analyses showed that the standardized electrodes gave a highly reproducible electrochemical response to a selective lectin, suggesting the promise of using anthraquinone-modified glycoligands for the impedance detection of lectins.

\section{Results and discussion}

As shown in Scheme 1, the desired anthraquinonyl glycoside (ZBW1) was synthesized by the $\mathrm{Cu}(\mathrm{I})$-catalyzed azide-alkyne 1,3-dipolar cycloaddition (CuAAC) of azido mannoside a [16] with dipropargyl anthraquinone b [5], followed by a de-acetylation, in $66 \%$ yield. For the sensor fabrication, the compound was simply spotted to the working electrode (pre-coated with a nano-graphene (nG)) of a screen printed electrode [17]. The presence of graphene may increase the adsorption of AG onto the working electrode [18]. Comparing to the conventional gold-thiol self-assembly, the strong $\pi$-interaction between graphene and anthraquinone [5] may provide a more facile and economic means for construction of self-assembled electrochemical biosensors due to the preclusion of using gold as the sensing platform. Upon formation of the sensors, the hydrophilic glycosyl moiety could expose to the environment for lectin recognition [5].

Voltammetry and EIS were used to monitor the sensor standardization. Three sets of electrodes with increasing current intensities (Figure 1d: $9.3 \mu \mathrm{A}$, Figure 1e: $15.2 \mu \mathrm{A}$ and Figure 1f: $19.9 \mu \mathrm{A}$ ) were made by spotting ZBW1 with different concentrations to the working electrode. The surface coverage areas ( $I$, adsorbed AQ species) of the different electrodes were determined to be $1.1 \times 10^{-9}$ (Figure 1a), $2.7 \times 10^{-9}$ (Figure 1b) and $6.9 \times 10^{-9}$ (Figure 1c) mol cm$~^{-2}$ by cyclic voltammetry $[3,5]$. EIS was then used to analyze the surface adhesion of a mannose-selective lectin, Concanavalin A (Con A), using $\left[\mathrm{Fe}(\mathrm{CN})_{6}\right]^{3-14-}$ as a redox probe [5]. We observed that the charge transfer resistance $\left(R_{\mathrm{ct}}\right)$ of all sets of electrodes decorated with the mannoside increased evidently in the presence of Con A (Figure 1g-i), suggesting the adhesion of the lectin onto the electrode surface. This is in good agreement with previous observations [5,11].

The lectin coverage efficiency $(\eta)$ was used to interpret the recognition, which was calculated by the following equation [19]:

$$
\eta=\left[R_{\mathrm{ct}}-R_{\mathrm{ct}(0)}\right] / R_{\mathrm{ct}}
$$

where $R_{\mathrm{ct}}$ and $R_{\mathrm{ct}(0)}$ are the charge transfer resistance in the presence and absence of lectin, respectively.

Notably, the electrodes with increasing current densities showed, consistently, increasing $R_{\mathrm{ct}}$ upon addition of Con A (Figure 1g: $34.8 \%$, Figure 1h: $49.7 \%$ and Figure 1i: 72.5\%). This implies that the current intensity of $\mathrm{AQ}$, which is related to the total amount of molecules adsorbed onto the electrode, corresponds well with the subsequent impedance change of the glyco-electrode in the presence of lectin. As a result, we produced series of electrodes (five for each set) with increasing current intensities of $9.6 \pm$ $0.2,15.4 \pm 0.5$ and $19.8 \pm 0.6 \mu \mathrm{A}$ (Figure 2a). The $\eta$ of the electrodes were determined to be $35.2 \pm 1.3,54.3 \pm 3.5$ and $72.9 \pm 2.4 \%$, respectively (Figure $2 b$ ). These data further suggest the following facts: 1 ) The electrodes with nearly identical current intensities show reproducible EIS response to a selective lectin, and 2) $\mathrm{AQ}$, while conjugated with a biomolecule, could be exploited as a signal reporter

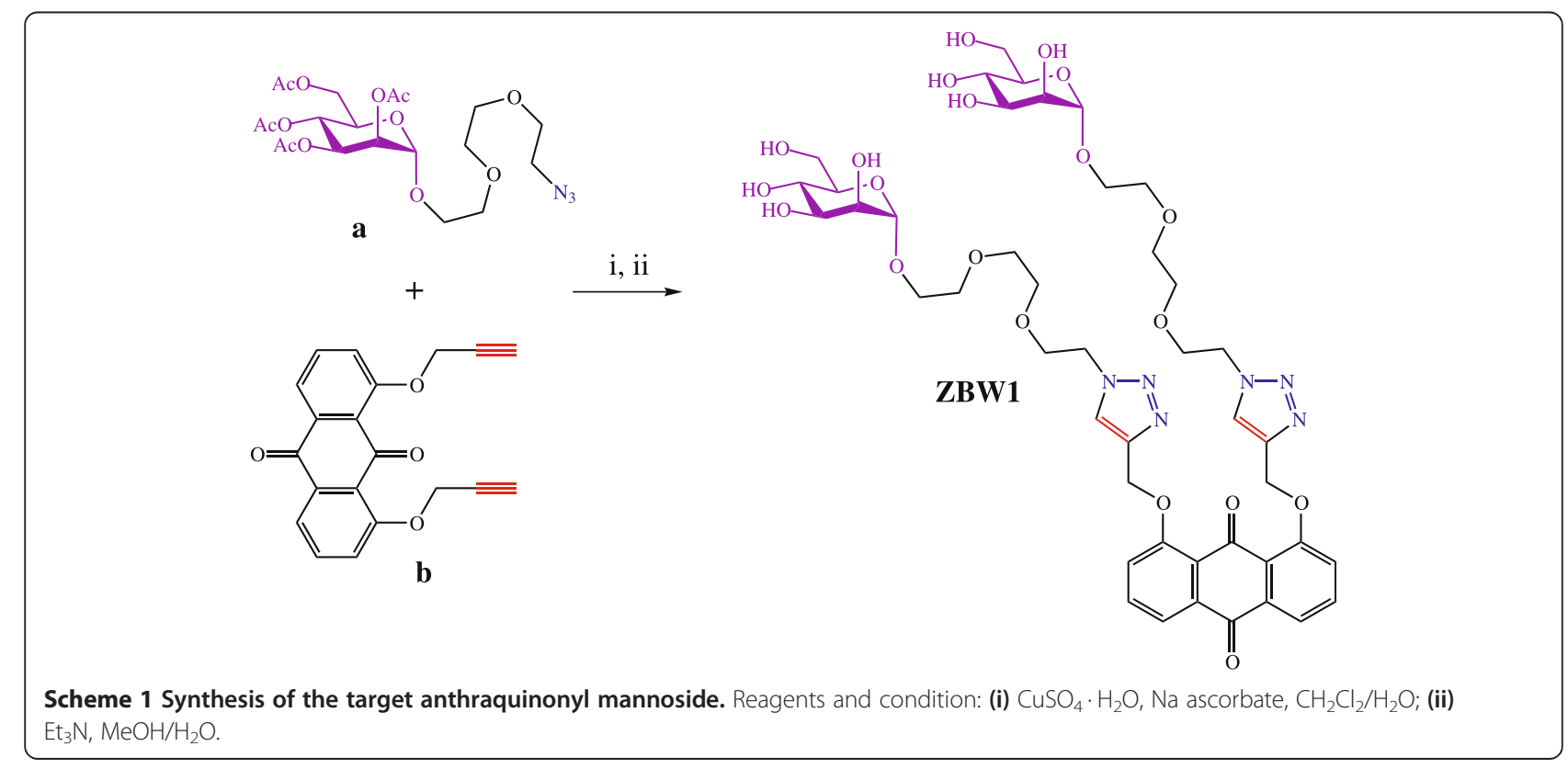



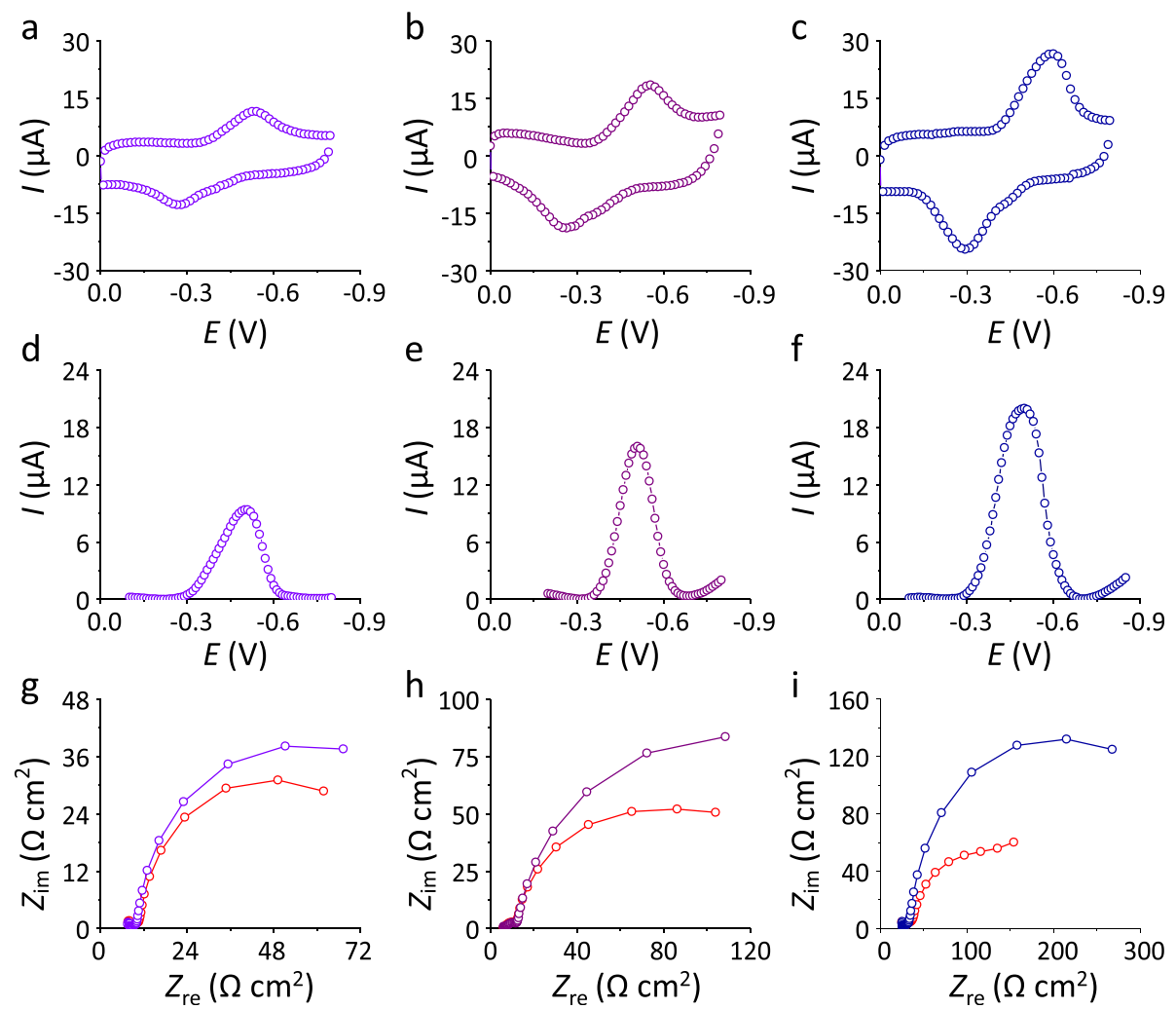

Figure 1 Representative electrochemical methods for the standardized detection of mannose-Con A interactions. Cyclic voltammetry (CV) of ZBW1 with a surface converge ( $/$ ) of (a) $1.1 \times 10^{-9} \mathrm{~mol} \mathrm{~cm}^{-2}$, (b) $2.7 \times 10^{-9} \mathrm{~mol} \mathrm{~cm}^{-2}$ and (c) $6.9 \times 10^{-9} \mathrm{~mol} \mathrm{~cm}$; Differential pulse voltammetry (DPV) of ZBW1 with a current intensity of (d) $9.3 \mu \mathrm{A}$, (e) $15.2 \mu \mathrm{A}$ and (f) $19.9 \mu \mathrm{A}$; Electrochemical impedance spectroscopy (EIS) of ZBW1 with a lectin coverage efficiency $(\eta)$ of $\mathbf{( g )} 34.8 \%$, (h) $49.7 \%$, and (i) $72.5 \%$ on graphene electrodes in the presence (colored) of Con A $(10 \mu \mathrm{M})$ (red plots stand for ZBW1-functionalized graphene electrodes in the absence of a lectin).

to standardize the EIS-based biosensor fabrication via voltammetry.

The complexation between AG and graphene was also characterized by various techniques. In the Raman spectra, the intensity ratio of the D band $\left(1355 \mathrm{~cm}^{-1}\right)$ to the $\mathrm{G}$ band $\left(1600 \mathrm{~cm}^{-1}\right)$ of the ZBW1-nG complex increased (0.92, Figure 3a) comparing to the bare $\mathbf{n G}(0.86$, Figure $3 \mathrm{~b}$ ). This suggests an increase in $\mathrm{sp}^{2}$-hybridization of the complex probably because of the stacking of the aromatic ZBW1 to the surface of graphene [4,5,20,21]. In
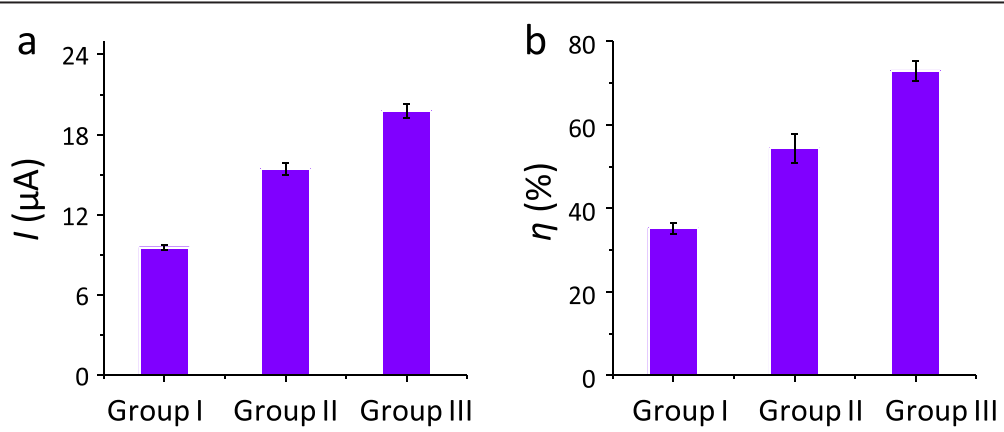

Figure 2 Standardized detection of mannose-Con A interactions via electrochemical impedance spectroscopy. (a) Averaged current density ( $)$ of ZBW1 decorated on the graphene electrode of different groups. (b) Averaged lectin coverage efficiency ( $\eta$ ) of the graphene electrode decorated with ZBW1 of different groups in the presence of Con A (10 $\mu \mathrm{M})$. The mean / for group I, II and II are $9.6 \pm 0.2,15.4 \pm 0.5$ and $19.8 \pm 0.6 \mu \mathrm{A}$, respectively. The mean $\eta$ for group I, II and II are $35.2 \pm 1.3,54.3 \pm 3.5$ and $72.9 \pm 2.4 \%$, respectively. The original DPV and EIS plots of group I, II and III are shown in Additional file 1: Figures S1, S2 and S3, respectively. 

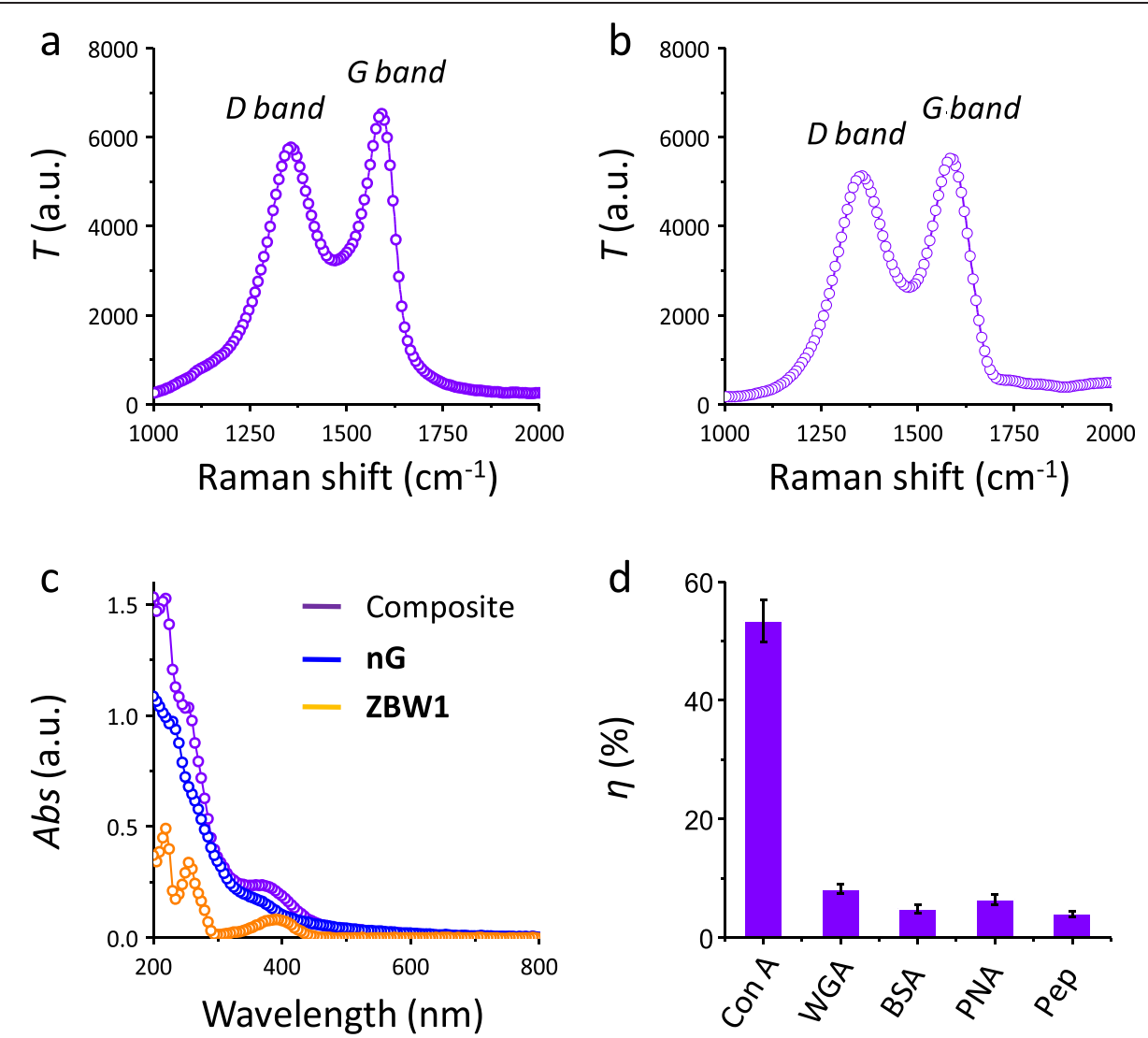

Figure $\mathbf{3}$ Characterization of the compound-graphene complex and sensor selectivity. Raman spectra of (a) nano-graphene (nG) and (b) nG complexed with ZBW1; (c) UV-Vis spectra of $\mathbf{n G}$, ZBW1 and the complex; (d) Selectivity of ZBW1- decorated graphene electrode for different proteins including the $\mathrm{N}$-acetyl glucosamine-selective wheat germ agglutinin (WGA), the galactose-selective peanut agglutinin (PNA), bovine serum albumin (BSA) and pepsin (Pep) determined by electrochemical impedance spectroscopy. The original ElS spectra are shown in Additional file 1: Figure 55.

the meanwhile, peaks characteristic of the stacking of AG to $\mathbf{n G}$ were observed in the UV-vis (red shift from $388 \mathrm{~nm}$ [orange] to $395 \mathrm{~nm}$ [violet] Figure 3c) and FTIR $\left(\tilde{v}=2350 \mathrm{~cm}^{-1}\right.$, Additional file 1: Figure S4) spectra of the ZBW1-nG complex. These results suggest the successful assembly of the AG-graphene complex. Furthermore, we observed that the CV and DPV of unmodified anthraquinone on the graphene electrode (Additional file 1: Figure S6) are in good agreement with those of ZBW1, suggesting the functionalization of the electrodes with the anthraquinone group.

We then tested the selectivity of the biosenor with a series of unselective lectins and proteins including the $\mathrm{N}$-acetyl glucosamine-selective wheat germ agglutinin (WGA), the galactose-selective peanut agglutinin (PNA), bovine serum albumin (BSA) and pepsin (Pep). As shown in Figure 3d, the electrode only showed an impedance change in the presence of the selective Con A with no insignificant response to the unselective proteins. This suggests the usefulness of the EIS sensor developed for the selective detection of lectins.

\section{Experimental section}

General

All purchased chemicals and reagents are of analytical grade. Nano-graphene (lateral diameters ranging from 1-10 $\mathrm{nm}$ ) was purchased from Nanjing XFNano Materials Tech. Co., Ltd. Solvents were purified by standard procedures. Reactions were monitored by TLC (thinlayer chromatography) using E-Merck aluminum precoated plates of Silica Gel. ${ }^{1} \mathrm{H}$ NMR spectrum was recorded on a Bruker AM-400 spectrometer using tetramethylsilane (TMS) as the internal standard (chemical shifts in parts per million). High resolution mass spectrum was recorded on a Waters LCT Premier XE spectrometer using standard conditions (ESI, $70 \mathrm{eV}$ ). High performance liquid chromatogram (HPLC) was taken on an Agilent 1100 equipment.

\section{Synthesis of ZBW1}

To a solution of $\mathbf{b}(250 \mathrm{mg}, 0.50 \mathrm{mmol})$ and a $(68.6 \mathrm{mg}$, $0.25 \mathrm{mmol})$ in a solvent mixture of $\mathrm{CH}_{2} \mathrm{Cl}_{2}(5 \mathrm{~mL})$ and $\mathrm{H}_{2} \mathrm{O}(5 \mathrm{~mL})$ were added $\mathrm{CuSO}_{4} \cdot 5 \mathrm{H}_{2} \mathrm{O}(2.0$ equiv.) and 
$\mathrm{Na}$ ascorbate (4.0 equiv.). This mixture was stirred over night and then diluted with $\mathrm{CH}_{2} \mathrm{Cl}_{2}$ and washed with brine. The combined organic layer was dried over $\mathrm{MgSO}_{4}$, filtered and concentrated in vacuum to provide a crude product. The product was purified by column chromatography $(\mathrm{EtOAc} / \mathrm{MeOH}=20: 1, \mathrm{v} / \mathrm{v})$ to give an intermediate as a yellow solid $(249.4 \mathrm{mg}, 0.19 \mathrm{mmol})$. To a solution of the intermediate in a solvent mixture of $\mathrm{MeOH}(5 \mathrm{~mL})$ and $\mathrm{H}_{2} \mathrm{O}(5 \mathrm{~mL})$ was added excessive $\mathrm{Et}_{3} \mathrm{~N}$. This mixture was stirred at room temperature for $36 \mathrm{~h}$. Then, solvent was removed in vacuum to directly afford ZBW1 as a yellow solid (148.5 mg, 2-step yield $66.4 \%) . R_{\mathrm{f}}=0.48(\mathrm{EtOAc} / \mathrm{MeOH}=1: 1, \mathrm{v} / \mathrm{v}) .{ }^{1} \mathrm{H}$ NMR $\left(400 \mathrm{MHz}, \mathrm{D}_{2} \mathrm{O}\right): \delta 8.02(\mathrm{~s}, 2 \mathrm{H}), 7.25-7.14(\mathrm{~m}, 6 \mathrm{H}), 5.06$ $(\mathrm{s}, 4 \mathrm{H}), 4.63(\mathrm{~s}, 2 \mathrm{H}), 4.51(\mathrm{t}, J=4.0 \mathrm{~Hz}, 4 \mathrm{H}), 3.83$ $(\mathrm{t}, J=4.0 \mathrm{~Hz}, 4 \mathrm{H}), 3.75-3.74(\mathrm{~m}, 2 \mathrm{H}), 3.69(\mathrm{~d}, J=2.0 \mathrm{~Hz}$, $1 \mathrm{H}), 3.66(\mathrm{~d}, J=2.0 \mathrm{~Hz}, 1 \mathrm{H}), 3.62(\mathrm{~d}, J=3.6 \mathrm{~Hz}, 1 \mathrm{H}), 3.61$ (s, 1H), 3.60-3.55 (m, 4H), $3.53(\mathrm{~s}, 1 \mathrm{H}), 3.51(\mathrm{~s}, 1 \mathrm{H}), 3.48$ (s, $1 \mathrm{H}), 3.42(\mathrm{t}, J=3.2 \mathrm{~Hz}, 6 \mathrm{H}), 3.36(\mathrm{~s}, 8 \mathrm{H}), 3.32-3.28$ (m, 1H). HR-ESI-MS: calcd. for $\left[\mathrm{C}_{44} \mathrm{H}_{58} \mathrm{~N}_{6} \mathrm{O}_{20}+\mathrm{Na}\right]^{+}$ 1013.3604, found 1013.3606. HPLC: $t_{\mathrm{R}}=3.9 \mathrm{~min}$ over 17 min of eluent (acetonitrile/ $\mathrm{H}_{2} \mathrm{O}=9: 1, \mathrm{v} / \mathrm{v}$ ), purity $96.4 \%$.

\section{Cyclic voltammetry (CV)}

CVs were recorded with a computer controlled $\mathrm{CHI}$ 1211B electrochemical station (Chenhua Co. Ltd., Shanghai, China) between $-0.8 \mathrm{~V}$ and $-0.2 \mathrm{~V}$ (vs. Ag/ $\mathrm{AgCl}$ ) at a scan rate of $100 \mathrm{mV} / \mathrm{s}$. The electrolyte (Tris$\mathrm{HCl}, 0.01 \mathrm{M}, \mathrm{pH}$ 7.3) used was degassed with $\mathrm{N}_{2}$ for $20 \mathrm{~min}$ before measurements. Screen-printed electrodes (SPEs) were pretreated in a PBS $(0.05 \mathrm{M}, \mathrm{pH} 7.0)$ containing $0.1 \mathrm{M} \mathrm{KCl}$ by applying an anodic potential of $2 \mathrm{~V}$ (vs. $\mathrm{Ag} / \mathrm{AgCl}$ ) for $200 \mathrm{~s}$, and were then washed with water three times. The circular area (2 $\mathrm{mm}$ in diameter) was used as the working electrode; the reference electrode was printed with $40 \% \mathrm{AgCl}$ in silver paste, and the auxiliary electrode printed with carbon ink. For functionalization of the SPEs, a drop $(4 \mu \mathrm{L})$ of aqueous $\mathbf{~ n G}$ solution was dripped onto the working electrode and dried under vacuum. Then a drop $(4 \mu \mathrm{L})$ of the aqueous ZBW1 solution was dripped onto the working electrode and dried under vacuum. The functionalized SPEs were finally immersed into Tris- $\mathrm{HCl}$ solutions for recording the CVs.

\section{Differential pulse voltammetry (DPV)}

DPVs were recorded with an amplitude of $0.05 \mathrm{~V}$, a pulse width of $0.2 \mathrm{~s}$, a standing time of $2 \mathrm{~s}$, and a scanning range from $-0.8 \mathrm{~V}$ to $-0.2 \mathrm{~V}$ in Tris $-\mathrm{HCl}(0.01 \mathrm{M}$, $\mathrm{pH}$ 7.3). For detection of analytes, a drop $(4 \mu \mathrm{L})$ of the Tris- $\mathrm{HCl}$ solution of ZBW1 $\left(5 \times 10^{-3} \mathrm{M}\right)$ was dripped onto the GO functionalized working electrode area of SPE, and then incubated for $30 \mathrm{~min}$. Then the electrodes were rinsed with the buffer solution three times, dried at room temperature, and then immersed in degassed buffer for measurement.

\section{Electrochemical impedance spectroscopy (EIS)}

EIS was performed with a ZAHNER apparatus in the presence of the $\left[\mathrm{Fe}(\mathrm{CN})_{6}\right]^{3-} /\left[\mathrm{Fe}(\mathrm{CN})_{6}\right]^{4-}(5 \mathrm{mM})$ redox couple in $0.1 \mathrm{M} \mathrm{KCl}$ solution in the frequency range of $10 \mathrm{mHz}$ to $100 \mathrm{KHz}$ (perturbation signal: $5 \mathrm{mV}$ ). All data collected were fitted with the software ZSimpWin. A drop $(4 \mu \mathrm{L})$ of the Tris- $\mathrm{HCl}$ solution of ZBW1 $(5 \times$ $10^{-3} \mathrm{M}$ ) was first dripped onto the graphene functionalized working electrode area of SPE, dried under vacuum, and then the Nyquist plots were recorded. For detection of the sugar-lectin interactions, a drop (Tris- $\mathrm{HCl}, 4 \mu \mathrm{L}$ ) of protein solution was dripped onto the ZBW1-nG cofunctionalized electrode, dried under vacuum, and the Nyquist plots recorded. Figure 4 shows the circuit model used to fit all Nyquist plots [19]:

\section{Fourier Transform Infrared Spectroscopy (FTIR)}

FTIR spectra were recorded on a Nicolet 380 FTIR spectrometer (Thermo Electron Corporation, USA). The samples were mixed with $\mathrm{KBr}$ and then compressed into pellets for analysis in the spectral range of $v=4000$ to $500 \mathrm{~cm}^{-1}$. All baselines of the spectra were corrected.

\section{Raman spectroscopy}

Raman spectra were performed on a Renishaw InVia Reflex Raman system (Renishaw plc, Wotton-under-Edge, UK) that employs a grating spectrometer with a Peltiercooled charge-coupled device (CCD) detector coupled to a confocal microscope, which were then processed with Renishaw WiRE 3.2 software. The Raman scattering was excited by an argon ion laser $(I=514.5 \mathrm{~nm})$.

\section{Conclusion}

In summary, we have reported the synthesis of an anthraquinonyl glycoside to fabricate EIS-based electrochemical sensors, where the AQ moiety served as a binder that promotes self-assembly of the glyco-ligands to the working electrode. Importantly, AQ also acted as a signal reporter that facilitates the sensor standardization.

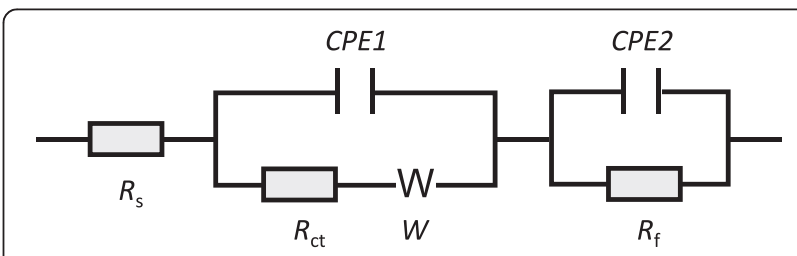

Figure 4 Circuit model used to fit the Nyquist plots. $R_{\mathrm{s}}$ is the solvent resistance, $R_{\mathrm{f}}$ the film resistance, $R_{\mathrm{ct}}$ the charge transfer resistance, CPE1 the film capacitance, CPE2 the double layer (the functional and electrolyte layer) capacitance, and $W$ the Warburg diffusion impedance. 
By using voltammetry and EIS, we determined that the electrodes with unified current signals showed reproducible impedance response to a selective lectin adhered to the electrode with high selectivity over other unselective proteins. This study provides insights into the simple construction of readily standardizable EIS sensors for the general, economic electrochemical analysis of ligand-protein interactions.

\section{Additional file}

Additional file 1: Supporting information.

\section{Competing interests}

The authors declare that they have no competing interests.

\section{Authors' contributions}

YTL, GRC and XPH conceived the idea. LC and BWZ performed experiments. $\mathrm{XPH}$ wrote the manuscript. YTL and GRC supervised the study. All authors commented on the paper. All authors read and approved the final manuscript.

\section{Acknowledgements}

We thank the 973 project (2013CB733700), the National Natural Science Foundation of China $(21176076,21202045)$, the Key Project of Shanghai Science and Technology Commission (13NM1400900) and the Fundamental Research Funds for the Central Universities.

Received: 9 July 2014 Accepted: 30 October 2014

Published online: 25 November 2014

\section{References}

1. For a recent review, see, Chen Y, Star A, Vidal S: Sweet carbon nanostructures: carbohydrate conjugates with carbon nanotubes and graphene and their applications. Chem Soc Rev 2013, 42:4532-4552.

2. Vedala H, Chen Y, Cecioni S, Imberty A, Vidal S, Star A: Nanoelectronic detection of lectin-carbohydrate interactions using carbon nanotubes. Nano Lett 2011, 11:170-175.

3. He XP, Wang XW, Jin XP, Zhou H, Shi XX, Chen GR, Long YT: Epimeric monosaccharide-quinone hybrids on gold electrodes toward the electrochemical probing of specific carbohydrate-protein recognitions. J Am Chem Soc 2011, 133:3649-3657.

4. Zhang HL, Wei XL, Zang Y, Cao JY, Liu S, He XP, Chen Q, Long YT, Li J, Chen $G R$, Chen K: Fluorogenic probing of specific recognitions between sugar ligands and glycoprotein receptors on cancer cells by an economic graphene nanocomposite. Adv Mater 2013, 25:4097-4101.

5. Li Z, Deng SS, Zang Y, Gu Z, He XP, Chen GR, Chen K, James TD, Li J, Long $Y T$ : Capturing intercellular sugar-mediated ligand-receptor recognitions via a simple yet highly biospecific interfacial system. Sci Rep 2013, 3:2293.

6. For a recent review, see, Bertók T, Katrlík J, Gemeiner P, Tkac J: Electrochemical lectin based biosensors as a label-free tool in glycomics. Microchim Acta 2013, 180:1-13.

7. Min IM, Choi L, Ahn KS, Kim BK, Lee BY, Kim KS, Choi HN, Lee WY: Electrochemical determination of carbohydrate-binding proteins using carbohydrate-stabilized gold nanoparticles and silver enhancement. Biosens Bioelectron 2010, 26:1326-1331.

8. Bertok T, Sediva A, Katrlik J, Gemeiner P, Mikula M, Nosko M, Tkac J: Label-free detection of glycoproteins by the lectin biosensor down to attomolar level using gold nanoparticles. Talanta 2013, 108:11-18.

9. Hu Y, Zuo P, Ye BC: Label-free electrochemical impedance spectroscopy biosensor for direct detection of cancer cells based on the interaction between carbohydrate and lectin. Biosens Bioelectron 2013, 43:79-83.

10. Oliveira MDL, Andrade CAS, Correia MTS, Coelho LCBB, Singh PR, Zeng X: Impedimetric biosensor based on self-assembled hybrid cystein-gold nanoparticles and CramoLL lectin for bacterial lipopolysaccharide recognition. J Colloid Interface Sci 2011, 362:194-201.
11. Loaiza OA, Lamas-Ardisana PJ, Jubete E, Ochoteco E, Loinaz I, Cabañero G, García I, Penadés S: Nanostructured disposable impedimetric sensors as tools for specific bimolecular interactions: sensitive recognition of concanavalin A. Anal Chem 2011, 83:2987-2995.

12. Bertok T, Gemeiner P, Mikula M, Gemeiner P, Tkac J: Ultrasensitive impedimetric based biosensor for glycoproteins containing sialic acid. Microchim Acta 2013, 180:151-159.

13. Zhang $X$, Teng $Y$, Fu Y, Zhang S, Wang T, Wang C, Jin L, Zhang W: Lectin-based electrochemical biosensor constructed by functionalized carbon nanotubes for the competitive assay of glycan expression on living cancer cells. Chem Sci 2011, 2:2353-2360.

14. Chen H, Xi F, Gao X, Chen Z, Lin X: Bienzyme bionanomultilayer electrode for glucose biosensing on functional carbon nanotubes and sugar-lectin biospecific interaction. Anal Biochem 2010, 403:36-42.

15. Zhang Y, Luo S, Tang Y, Yu L, Hou KY, Cheng JP, Zeng X, Wang PG: Carbohydrate-protein interactions by "clicked" carbohydrate selfassembled monolayers. Anal Chem 2006, 78:2001-2008.

16. Otaman $\mathrm{O}$, Boullanger $P$, Lafont $D$, Hamaide $T$ : New amphiphilic glycopolymers based on a polycaprolactone-maleic anhydride copolymer backbone: characterization by ${ }^{15} \mathrm{~N}$ NMR and application to colloidal stabilization of nanoparticles. Macromol Chem Phys 2008, 209:2410-2422.

17. Song W, Li DW, Li YT, Li Y, Long YT: Disposable biosensor based on graphene oxide conjugated with tyrosinase assembled gold nanoparticles. Biosens Bioelectron 2011, 26:3181-3186.

18. Huang X, Zeng Z, Fan Z, Liu J, Zhang H: Graphene-based electrodes. Adv Mater 2012, 24:5979-6004.

19. Cai L, Fu Q, Shi R, Tang Y, Long TY, He XP, Jin Y, Liu G, Chen GR, Chen K: 'Pungent' copper surface resists acid corrosion in strong $\mathrm{HCl}$ solutions. Ind Eng Chem Res 2014, 53:64-69.

20. He XP, Deng Q, Cai L, Wang CZ, Zang Y, Li J, Chen GR, Tian H: Fluorogenic resveratrol-confined graphene oxide for economic and rapid detection of Alzheimer's disease. ACS Appl Mater Interfaces 2014, 6:5379-5382.

21. Sun X, Zhu B, Ji DK, Chen Q, He XP, Chen GR, James TD: Selective fluorescence detection of monosaccharides using a material composite formed between graphene oxide and boronate-based receptors. ACS Appl Mater Interfaces 2014, 6:10078-10082.

doi:10.1186/s13065-014-0067-y

Cite this article as: Zhu et al:: Anthraquinonyl glycoside facilitates the standardization of graphene electrodes for the impedance detection of lectins. Chemistry Central Journal 2014 8:67.

Publish with ChemistryCentral and every
scientist can read your work free of charge
"Open access provides opportunities to our
colleagues in other parts of the globe, by allowing
anyone to view the content free of charge."
W. Jeffery Hurst, The Hershey Company.
- available free of charge to the entire scientific community
- peer reviewed and published immediately upon acceptance
- cited in PubMed and archived on PubMed Central
- yours - you keep the copyright
submit your manuscript here:
http://www.chemistrycentral.com/manuscript/

